\title{
Evasão fiscal, grupos econômicos de fato e o federalismo fiscal brasileiro
}

\author{
Tax evasion, economic groups in fact and brazilian fiscal federalism
}

\author{
Zélia Luiza Pierdoná* \\ José Carlos Francisco* \\ luri Daniel de Andrade Silva ${ }^{*+*}$
}

\section{Resumo}

Partindo do problema concernente às alternativas para a solução da crise fiscal brasileira, este estudo tem como hipótese a existência de dois caminhos que se complementam. O primeiro envolve ajustes na despesa pública pelo controle da execução orçamentária e por alterações estruturais ( $p$. ex., reforma da previdência). O segundo abarca o desafio de aumentar a efetividade da arrecadação, sem aumento formal da carga tributária, mediante utilização de mecanismos que reforcem a performance fiscal. Em busca do aperfeiçoamento da boa administração tributária, as divisas e as guerras, que, por tanto tempo, opuseram as entidades federativas, devem ceder espaço a um modelo colaborativo de federalismo que integre a União, como police decision maker, e os estados e municípios, como police makers, formatando-se um sistema de combate preventivo e repressivo à formação de grupos econômicos de fato voltados à evasão fiscal. Segmentando a hipótese deste estudo e utilizando o método lógico-dedutivo, este artigo tem por objetivo analisar grupos econômicos de fato, buscando proposições para o combate preventivo e repressivo da sonegação fiscal, no contexto do federalismo fiscal brasileiro, em favor da superação da crise arrecadatória, bem como da otimização dos mecanismos de financiamento dos direitos fundamentais.

Palavras-chave: Grupo econômico de fato. Evasão fiscal. Responsabilidade tributária. Dever jurídico fundamental de pagar tributos. Financiamento dos direitos.

\section{Abstract}

The search for alternatives to the solution of the Brazilian fiscal crisis encompasses two complementary paths. The first involves adjustments in public spending, through controls on budget execution; as well as structural changes, such as pension reform. The second, in turn, addresses the challenge of increasing tax collection without increasing the tax burden, through the use of mechanisms that reinforce fiscal performance. In pursuit of improvement of good tax administration, questions which, for so long opposed the federative entities, should give way to a collaborative model of federalism that integrates the Union as a police decision maker, and the federative States and Municipalities, as police makers, building a system of preventive and repressive combat to the formation of economic groups in fact focused on tax evasion. Therefore, this paper aims to analyze economic groups, using logical thought and deductive reasoning and also seeking solutions for preventive and repressive combat of tax evasion, in the Brazilian fiscal federalism, in order to overcomes tax crises as well as optimizes the instruments of fundamental rights' funding.

Keywords: Economic group in fact. Tax evasion. Tax liability. Fundamental legal duty to pay taxes. Rights financing.

Doutora em Direito pela Pontifícia Universidade Católica de São Paulo. Mestre em Direito pela Pontifícia Universidade Católica de São Paulo. Professora da Faculdade de Direito da Universidade Presbiteriana Mackenzie e do Programa de Pós-graduação em Direito Político e Econômico da mesma Universidade. Estágio de pós-doutorado na Universidade Complutense de Madri. Procuradora Regional da República em São Paulo. São Paulo - SP - Brasil. E-mail: zelia.pierdona@hotmail.com.

- Doutor em Direito pela Universidade de São Paulo (2003). Mestre em Direito pela Universidade de São Paulo (1998). Professor da Universidade Presbiteriana Mackenzie (graduação, mestrado e doutorado). Estágio de pós-doutorado na Université de Paris 1 - Panthéon-Sorbonne (2008/2009). Membro do Instituto Pimenta Bueno - Associação Brasileira dos Constitucionalistas. Associado-dirigente do Instituto Brasileiro de Estudos Constitucionais - IBEC. Desembargador Federal no Tribunal Federal Regional da $3^{\mathrm{a}}$ Região. São Paulo - SP - Brasil. E-mail: josecarlos.francisco@ mackenzie.br.

... Mestre em Direito Político e Econômico pela Universidade Presbiteriana Mackenzie. Especialista em Direito Tributário. Professor de Direito da Universidade de Mogi das Cruzes. Procurador da Fazenda Nacional. São Paulo - SP - Brasil. E-mail: iuridaniel84@gmail.com. 


\section{Introdução}

Os abusos de forma e de personalidade jurídica, a confusão patrimonial e a simulação, além de institutos jurídicos diversos, têm sido utilizados como subterfúgio formal para a prática de atos que objetivam lesionar o patrimônio público e o sistema tributário nacional.

As estruturas ilícitas espraiam-se pelo território nacional, aproveitando-se dos vácuos fiscalizatórios decorrentes da rigidez que configura o atual modelo federativo, e crescem sobre o substrato das diferenças de interesses fiscais que contrapõem a União, o Distrito Federal, os estados e os municípios, deixando um rastro de prejuízos que, imediatamente, refletem-se na efetivação de direitos fundamentais, especialmente os sociais.

Nesse contexto, partindo do problema concernente às alternativas para a solução da crise fiscal brasileira (agravada pelos efeitos da pandemia decorrente do novo coronavírus, com extraordinário aumento de gastos públicos e expressiva redução da arrecadação tributária) e utilizando o método lógico-dedutivo, este estudo tem como hipótese demonstrar que o uso de mecanismos no combate a grupos econômicos de fato ilegítimos - a saber, estruturas baseadas em múltiplas pessoas jurídicas desprovidas de propósito negocial (business purpose) e voltadas à evasão fiscal - são eficientes para o combate preventivo e repressivo da sonegação fiscal no contexto do federalismo fiscal brasileiro para superação da crise arrecadatória atual, bem como para a otimização dos mecanismos de financiamento dos direitos fundamentais.

É importante ressaltar, desde já, que os grupos econômicos, per si, não são necessariamente ilícitos ou voltados à sonegação, porque podem surgir por diversas circunstâncias (p. ex., crescimento desordenado de negócios, sem o propósito de lesar interesses públicos ou privados). Neste estudo, recorta-se a análise para aqueles formados sem propósito negocial e vocacionados à sonegação, nos termos do art. 50 do Código Civil.

A análise, quanto à abordagem do federalismo, utiliza os estudos empreendidos por Marta Arretche (2012) e Alan Tarr (2009). Parte, ademais, do pressuposto segundo o qual os institutos devem ser interpretados para além da forma jurídica, não se podendo ignorar a análise consequencial e econômica sobre os fenômenos de direito, conforme sustentado pela Escola de Chicago. ${ }^{1}$ Por fim, entende o adimplemento tributário como um dever jurídico fundamental, necessário à sustentação do Estado fiscal, conforme lições de Casalta Nabais (1998).

O tema é de grande relevância para o enfrentamento da crise fiscal, fomentando a concepção de uma cultura dialógica entre os entes federativos ${ }^{2}$ por meio da formação de redes de coordenação inteligentes, voltadas ao combate eficiente da evasão fiscal, a fim de que se obtenha otimização na arrecadação, a qual se volta ao financiamento dos direitos.

\section{Estado fiscal e direitos fundamentais: os direitos na perspectiva do financiamento}

A configuração do Estado que derivou do término da Segunda Guerra Mundial toma por pressuposto a compreensão teleológica. O Estado deixou de ser apenas garantidor (com prestações negativas) de fatores liberais e passou a ser agente ativo e meio para alcance de objetivos relacionados à realização das potencialidades das pessoas. Observe-se que esse modelo de Estado, que se afirma em meados do século XX, é objeto de reestruturação na pósmodernidade, mas não corresponde ao tratado neste estudo. ${ }^{3}$

As diversas constituições estatais expressaram a preocupação com o ser humano, quer protegendo-o em face do Estado, quer concebendo obrigações prestacionais deste, mediante o fortalecimento da teoria dos direitos sociais, sendo a Constituição mexicana de 1917 e a Constituição de Weimar, de 1919, marcos iniciais (com antecedentes, como a Poor Law inglesa, de 19/12/1601, remodelada em 1834, e a Constituição francesa de 1848). Aliás, a moderna dogmática dos direitos fundamentais apregoa a necessidade de proteção do indivíduo, inclusive em relação a pessoas não estatais, conforme sustentam os defensores da eficácia horizontal dos direitos fundamentais (SARLET, 2008).

No Brasil, a realidade exposta é claramente percebida a partir da análise do texto constitucional de 1988. Ali, cidadania e dignidade da pessoa humana foram erigidas como fundamentos do Estado brasileiro, 
sendo a república e o federalismo instrumentos políticos voltados à realização de tais misteres. A dignidade humana é o escopo do sistema estatal constitucional, devendo ser alcançada não apenas por meio da construção de institutos formais ligados à democracia representativa, mas também pela efetivação dos direitos.

O fortalecimento dos direitos fundamentais é a marca dos tempos hodiernos. Os arranjos estatais voltam-se, essencialmente, ao desenvolvimento da cidadania, e o discurso de efetividade assume os cenários acadêmicos. Sob o ângulo da força normativa da Constituição, os refluxos de discursos e de eventuais movimentos políticos exaltados (de direita e de esquerda) são capazes de mover políticas estatais apenas dentro dos limites da abertura semântica permitida pelo ordenamento jurídico, e por isso não podem abdicar da proteção estatal a hipossuficientes.

Aduz-se a objetivação de direitos fundamentais para expressar a ideia de que todo o ordenamento tem como vigas mestras a cidadania e a dignidade da pessoa humana. Nesse sentido, os ramos dogmáticos do Direito, outrora apenas edificados sob o enfoque positivista da representação e da legalidade, passam a compreender o ordenamento a partir de teorias sobre direitos fundamentais.

As velhas dicotomias, a exemplo daquela que perfilava em lados opostos o público e o privado, perdem importância diante do novo enfoque. Agora, o público e o privado, antes vislumbrados como meios contrapostos, tornam-se instrumentos aliados a serviço da efetivação dos direitos (notadamente pelas funções sociais da propriedade e da empresa), superando-se concepções clássicas que, por séculos, influenciaram a construção dogmática do Direito Privado, do Direito Administrativo e do Direito Tributário. Grandes transformações se afirmaram no âmbito do Direito Público, ponderando os dogmas da supremacia e da indisponibilidade do interesse público, com o postulado da proporcionalidade. ${ }^{4}$ Nesse sentido, a lição de Di Pietro (2006, p. 20):

Parece que o que muda é principalmente a ideologia, é a forma de conceber o Estado e a Administração Pública. Não se quer mais o Estado prestador de serviços; quer-se o Estado que estimula, que ajuda, que subsidia a iniciativa privada; quer-se a democratização da Administração Pública pela participação dos cidadãos nos órgãos de deliberação e de consulta e pela colaboração entre público e privado na realização das atividades administrativas do Estado; quer-se a diminuição do tamanho do Estado para que a atuação do particular ganhe espaço, quer-se a flexibilização dos rígidos modos de atuação da Administração Pública para permitir maior eficiência; quer-se a parceria entre o público e o privado para substituir-se Administração Pública dos atos unilaterais, a Administração Pública autoritária, verticalizada, hierarquizada.

Também Odete Medauar (2017, p. 371) identifica as grandes transformações:

\begin{abstract}
Ante as transformações advindas nos temas clássicos do Direito Administrativo e a ascensão de novos temas a partir de fins dos anos 80 do século XX, em especial, os princípios da proporcionalidade, da razoabilidade, a consensualidade (incluindo os meios consensuais de solução de conflitos), a governança, além do foco direcionado ao cidadão (e não ao poder), mostra-se notório ser inviável cogitar-se da supremacia do interesse público, por incompatibilidade às novas e contemporâneas feições deste ramo jurídico e, no Brasil, também por fugir aos parâmetros da Constituição de 1988.
\end{abstract}

Nessa configuração teleológica de Estado, pautada por teorias dos direitos fundamentais, há certamente engrenagens que não se podem olvidar. Nesse sentido, a hipertrofia dos direitos, sem a observância de aspectos econômicos, pode tornar histérico e vazio o discurso (DUQUE, 2014, p. 97), tendendo à geração do colapso e do descrédito do próprio sistema de efetivação.

Nesse ambiente prolifera o efeito backlash, tanto no campo político quanto no judicial, que procura a vanguarda na defesa dos direitos fundamentais. Como efeito colateral de decisões judiciais em temas que dividem a opinião pública, até mesmo conclusões de vanguarda na defesa dos direitos fundamentais podem provocar reações contrárias com forte apelo emocional, repercutindo na opinião pública e em escolhas

Ainda acerca da alteração do eixo metodológico do direito administrativo, abandonando-se o norte da supremacia do interesse público, em favor da proporcionalidade, conferir: Godoy (2017); Porto (2016); Binenbojm (2005). 
eleitorais conservadoras, resultando, ao final, em leis potencialmente capazes de criar situação normativa ainda pior do que a que havia antes das decisões judiciais questionadas (efeito backlash). ${ }^{5}$

De fato, o pressuposto do Estado teleológico reside no financiamento dos direitos, quer sejam liberdades negativas, quer sejam prestações (HOLMES; SUNSTEIN, 2000). O estado finalístico de direitos fundamentais é também o Estado fiscal, sendo os direitos e o respectivo financiamento duas faces de uma mesma moeda. Quem quer os fins - a saber, os direitos - fornece os meios, quais sejam, as fontes de custeio, porque os direitos sociais são construídos a partir de premissas jurídicas solidárias, das quais derivam deveres mútuos entre entes estatais (na perspectiva do modelo federativo cooperativo e colaborativo com segmentos privados) e toda a sociedade (envolvendo o comprometimento concreto e útil da propriedade e da empresa com suas funções sociais).

Eis a razão pela qual o catálogo de direitos (assim como os direitos não catalogados) é seguido por regras e princípios concernentes ao financiamento, por meio da edificação de um sistema tributário nacional, que devem ser preferencialmente conjugados pela teoria externa de direitos fundamentais (porque a ponderação aparece como exigência argumentativa no art. 20 e seguintes da LINDB e no art. 489, §2 do Código de Processo Civil). ${ }^{6}$

Acerca do Estado fiscal e do dever jurídico fundamental de pagar tributos, Casalta Nabais (1998, p. 192) registrou:

[...] Pois, sendo o estado fiscal o estado cujas necessidades financeiras são essencialmente cobertas por impostos, facilmente se compreende que ele tem sido (e é) a regra do estado moderno. Todavia, se é certo que este, pela própria natureza da realidade econômica moderna, é necessariamente um estado financeiro - um estado cujas necessidades materiais são cobertas por meio de meios de pagamento, ou seja, de dinheiro que ele obtém, administra e aplica, não é menos certo que ele nem sempre se apresenta como um estado fiscal, havendo estados que claramente configuraram (ou configuram) verdadeiros estados proprietários, produtores ou empresariais.

Sendo assim, compreender os problemas referentes ao financiamento do Estado implica dimensionar o real e responsável alcance dos direitos fundamentais. Afinal, Holmes e Sustein (2000) já demonstraram que levar a sério os direitos pressupõe considerar o aspecto da escassez de recursos.

Observa-se, contudo, que o desenvolvimento da teoria dos direitos fundamentais, no Brasil, tem sido pautado pelo discurso, pela linguagem e pela dogmática analítica, desconsiderando-se o substrato econômico que permeia a efetivação. Os resultados são a consagração de direitos desprovidos de efetividade real, eis que carentes de substrato financeiro, bem como a hipertrofia de direitos classistas, com a consequente sobrecarga do sistema previdenciário. Em suma, há importante preocupação com os direitos e pouca atenção aos deveres jurídicos pertinentes aos correspondentes custeios, legando a perspectiva legítima do federalismo cooperativo com a imprescindível colaboração da sociedade civil.

Para além da dogmática analítica, é mister compreender holisticamente os direitos e os deveres igualmente fundamentais a partir da análise de custos e externalidades econômicas e suas respectivas responsabilidades (ZYKBERSTAJN; SZTAJN, 2005, p. 3). Direitos são resultados de planejamento fiscal e equilíbrio orçamentário. Portanto, a arrecadação tributária, assim como a otimização da realização de despesas públicas, está na base da consagração do modelo teleológico estatal colaborativo com os agentes do sistema econômico (em especial, empresas compreendidas sob a ótica de suas funções sociais).

O sistema tributário encontra-se no cerne dos discursos que concentram os maiores embates jurídicos, a saber, entre a implementação de direitos fundamentais e a consagração de um regime de responsabilidade fiscal. Com efeito, se todo direito está amparado em um dever correlato, os direitos fundamentais encontramse ancorados no correlato dever jurídico fundamental de pagamento de impostos - conforme tese defendida

Sobre o tema, ver Klarman (2011). Embora Michael Klarman descreva casos de julgamentos progressistas em sua exposição, a reação política adversa não é necessariamente conservadora, mas contrária à linha de entendimento firmada pelo Poder Judiciário, de modo que o backlash pode se dar por diferentes orientações ideológicas.

6 Sobre a teoria externa para a definição de limites ao exercício de direitos fundamentais no Brasil, ver Sarlet (2008). 
por Casalta Nabais, ${ }^{7}$ e que parece óbvia sob a perspectiva do modelo jurídico solidário e colaborativo positivado no ordenamento constitucional brasileiro.

\section{Performance fiscal e o custeio dos direitos}

É uma certeza matemática que o desequilíbrio fiscal impacta a implementação de direitos, sobretudo daqueles de caráter social. Segurança, saúde, educação, previdência, moradia e tantos outros direitos dependem de fontes de custeio e, sem contrapartida, não há partida. Sem recursos, o ordenamento jurídico não é suficiente para realizar concretamente os avanços sociais.

Na doutrina alemã, aliás, o princípio da reserva do possível, erigido a partir de numerus clausus, foi concebido para servir como critério de definição do que razoavelmente se pode exigir do Estado, observando-se, entre outros, o aspecto financeiro da prestação (SARLET, 2008). No direito alemão, há o claro reconhecimento jurídico de que o custo impacta a análise da própria existência do direito, conquanto seja recorrente sustentarse que se deve guardar sempre certo "mínimo existencial", de impreciso conteúdo jurídico. ${ }^{8}$

A crise fiscal tem afetado Estados de todo o mundo, agravada em expressivas proporções com o aumento de gastos e com a diminuição da arrecadação tributária em decorrência da pandemia causada pelo novo coronavírus. O problema é sentido não somente em países em desenvolvimento, variando tão somente o grau de intensidade:

A crise da dívida pública foi deflagrada em 2010, com a crise da dívida grega. Em seguida, a Irlanda também revelou sua situação calamitosa. Ela já atingiu a maioria dos estados europeus. Países importantes da Zona do Euro acumularam dívidas impagáveis, como é o caso da ltália, cuja dívida pública em 2011 já atingia cerca de $120 \%$ de seu Produto Interno Bruto. O mesmo ocorre com a Espanha, onde a dívida interna representou em 2012 o equivalente a 85,5\% do PIB e 90,5\% para 2013. Na França, conforme dados estatísticos divulgados pelo Instituto Nacional de Estatística e Estudos Econômicos (Insee), a dívida pública totalizou quase 90\% do PIB (FILIPPO, 2016, p. 29).

Eis o problema: a questão da crise fiscal afeta diretamente a efetividade dos direitos fundamentais. Duas hipóteses emergem como soluções que se complementam para o restabelecimento do equilíbrio fiscal. A primeira delas "arrasta multidões às ruas e inspira lágrimas em ministros e governantes". O comentário foi tecido por Luciano Gomes Filippo, em referência ao choro de Elsa Fornero, ministra italiana do trabalho, quando, em 2011, anunciou reformas previdenciárias e aumento de impostos como medidas de austeridade, voltadas a reduzir a dívida pública (FILIPPO, 2016, p. 30). Essa via envolve cortes de gastos que afetam direitos sociais - respeitado o mínimo existencial - e reformas estruturais na previdência social.

No Brasil, o referido caminho foi trilhado, por exemplo, por meio da Emenda Constitucional n. ${ }^{\circ}$ 95/2016, que limitou os gastos públicos. Na mesma linha, incluem-se as desvinculações de receitas da União, atualmente disciplinada pelas Emendas Constitucionais n. ${ }^{\circ}$ 93/2016 e $n .{ }^{\circ} 103 / 2019$, e as sucessivas reformas previdenciárias (a última, feita pela Emenda Constitucional n. ${ }^{\circ}$ 103/2019).

A segunda via, por sua vez, é atrelada ao fortalecimento dos mecanismos de arrecadação tributária. O desafio consiste em aumentar a efetividade da arrecadação sem o aumento formal da carga tributária, considerando o atual estado de estrangulamento fiscal dos setores produtivos. Com efeito, em estudo mais recente da série histórica consolidada pela Receita Federal do Brasil, verificou-se que a carga tributária brasileira correspondeu a 32,43\% do Produto Interno Bruto em 2017 (BRASIL, 2018a).

A ideia consiste em desenvolver técnicas que aumentem a performance fiscal, mediante a realização da boa administração, gerando efetividade nos sistemas arrecadatórios. Sob o prisma da eficiência,

"[...] Há, isso sim, o dever de todos contribuírem, na medida da sua capacidade contributiva, para as despesas a realizar com as tarefas do estado. Como membros da comunidade, que constitui o estado, ainda que apenas em termos econômicos (e não políticos), incumbe-lhes, pois, o dever fundamental de suportar os custos financeiros da mesma, o que pressupõe a opção por um estado fiscal, que assim serve de justificação ao conjunto dos impostos, constituindo estes o preço (e, seguramente, um dos preços mais baratos) a pagar pela manutenção da liberdade ou de uma sociedade civilizada" (NABAIS, 1998, p. 186). Vale observar que Nabais aduz a "impostos", uma vez que a obra é direcionada, a princípio, ao sistema tributário português. Considerando-se o sistema tributário brasileiro desenhado na Constituição de 1988 , o mais adequado é utilizar o gênero tributo, em razão, principalmente, da participação das contribuições sociais no montante arrecadado pela União.

8 Há quem tenha tentado dimensionar o conteúdo jurídico do mínimo existencial. Nesse sentido, ver Barcellos (2008). 
destaca Filippo (2016), a segunda solução trata mais adequadamente do problema da crise fiscal, à luz do ótimo de Pareto, considerando que alcança resultado sem causar prejuízo aos cidadãos que já cumprem regularmente suas obrigações, pois as medidas se destinam a combater irregularidades. Sobre o princípio da boa administração, convém registrar a lição de Filippo (2016, p. 32):

\begin{abstract}
A expressão boa administração é muito comum na Itália (buona administrazione), tendo sido incorporada na Constituição e 1948, de onde o constituinte brasileiro se inspirou para consagrá-la (sob o nome de eficiência administrativa) na Constituição de 1988. No direito inglês, a expressão também se faz presente (good administration). Na Espanha, a buena administración constitui garantia positivada em diversos diplomas legais, como o estatuto geral do agente público [...].
\end{abstract}

A eficiência fiscal consiste em vetor principiológico presente no texto constitucional, conforme identificou Heleno Taveira Torres (2006, p. 14):

Para comprovar que essa exigência de performance da Administração Tributária encontra-se prevista como dever de orientação da legislação brasileira, no que tange às receitas, o artigo 52, $\mathrm{XV}$, estabelece a competência do Senado Federal para avaliar periodicamente a funcionalidade do Sistema Tributário Nacional, em sua estrutura e seus componentes, e o desempenho dos Municípios. Somados esses dispositivos com o art. 37, que consagrou o princípio da eficiência na Administração Pública como princípio fundamental, patente que a instauração de controles do orçamento por 'resultados' (performance) sempre existiu. Falta a atitude de execução firme e qualificada, inclusive quanto às metas, programas e objetivos, no que sua impositividade é plena.

Aprimorar a performance da arrecadação tributária no Brasil não é tarefa simples, sobretudo em razão da ausência de cultura dialógica efetiva entre a administração tributária e o contribuinte, bem como da excessiva complexidade dos processos administrativos e judiciais tributários. Contudo, nos últimos anos, o advento de novos instrumentos de otimização arrecadatória indica que o investimento na eficiência dos sistemas de arrecadação é um caminho viável.

De fato, na esfera federal, diversos mecanismos foram recentemente configurados para fins de obtenção de maiores resultados arrecadatórios, com destaque para: o regime diferenciado de cobrança de créditos (RDCC), o rating da dívida ativa, o protesto extrajudicial de dívida e a averbação pré-executória, entre outros. A Receita Federal do Brasil e a Procuradoria da Fazenda Nacional também se reestruturaram com a criação de áreas para acompanhamento de grandes contribuintes.

Nesse sentido, os dados expostos pela Procuradoria-Geral da Fazenda Nacional, em 2018, apontam para um incremento arrecadatório federal de $75,4 \%$ em relação ao ano pretérito, após o fortalecimento do protesto extrajudicial de dívida ativa e o regime diferenciado de cobrança de créditos (BRASIL, 2018b, p. 9). Entretanto há muito a avançar, inclusive na adoção de medidas para o enfrentamento da sonegação fiscal.

\title{
4 Sonegação fiscal: uma afronta ao princípio da isonomia
}

Segundos dados expostos no domínio eletrônico "Quanto custa o Brasil?" (SONEGÔMETRO, 2020), somente no ano de 2018, entre 01 de janeiro de 2018 e 18 de setembro de 2018, estima-se que a quantia de $\mathrm{R} \$$ 408.638.345.761,08 (quatrocentos e oito bilhões, seiscentos e trinta e oito milhões, trezentos e quarenta e cinco mil, setecentos e sessenta e um reais e oito centavos) deixou de ser recolhida ao erário. Embora a sonegação se faça por diversos modos e mecanismos ilegítimos, o uso de grupos econômicos de fato alavanca a evasão tributária, por envolver grandes volumes de transações com duas ou mais empresas.

Conquanto não se tenha resultados de pesquisas empíricas quantitativas demonstrando que o combate a grupos econômicos de fato gerará arrecadação importante, intuitivamente se pode afirmar que se trata de uma das mais relevantes medidas que devem ser tomadas para melhorar a performance do sistema de arrecadação, justamente porque o volume de transações e de sonegações realizadas por grupos econômicos é potencialmente maior que a praticada por empresas isoladamente.

Conforme explicitado, o inadimplemento fiscal afeta sensivelmente a efetividade dos direitos fundamentais, considerando o substrato econômico que permeia a implementação de políticas públicas. 
Sendo assim, atinge os mais básicos direitos, destruindo o futuro dos menos favorecidos, os quais têm acesso à saúde, apenas por meio do Sistema Único de Saúde, e à assistência social, subsistemas não contributivos da seguridade social.

Em prisma diverso, a sonegação (especialmente por grupos econômicos de fato) desequilibra a concorrência, a igualdade e a justiça fiscal em razão da desleal prática predatória de preços subsidiada pelo "lucro" do ilícito tributário, em desfavor dos players que regularmente adimplem as obrigações tributárias. Por outro lado, desestimula o pagamento regular e voluntário de tributos, gerando um círculo vicioso que aprofunda o abismo do inadimplemento e afronta o dever jurídico fundamental de pagar tributos - alicerce financeiro que sustenta a dignidade da pessoa humana.

Não há ordem econômica, justiça fiscal ou isonomia tributária real que resista a um quadro tão assustador de inadimplemento e de evasão. Pertinente, portanto, a crítica tecida por João Ricardo Catarino (2016, p. 08):

\begin{abstract}
E foi assim que também erigimos a igualdade tributária e então pensamos: agora sim! Se realmente todos pagam segundo os seus haveres, então isso quer dizer várias coisas: que todos pagam e que todos pagam segundo o que podem! Pura mentira! Imposto é hoje coisa de pobre, ou melhor, da classe média. Os muito ricos não pagam impostos, nunca pagaram e, provavelmente nunca pagarão. A prová-lo estão por aí os inúmeros casos de planejamento fiscal, o abuso das formas e dos meios, as instituições financeiras sedentas de, a qualquer preço e de qualquer jeito, segurar em suas mãos a liquidez deste mundo, mesmo que seja preciso fechar os olhos a tudo e a todos, transformar nomes em meros números e por aí adiante. Coitada da igualdade tributária, num mundo onde somos e sempre seremos todos profundamente desiguais.
\end{abstract}

O tema da sonegação adquire, no caso brasileiro, ainda mais relevo, em razão de dois aspectos.

Primeiramente, a forma, não raro, tem sido utilizada para escamotear intenções evasivas. Com efeito, há diversos casos reconhecidos pelos tribunais judiciários pátrios e pela administração tributária em que foi demonstrada a divergência entre a forma negocial utilizada para celebração de atos jurídicos e a real intenção evasiva.

No propósito de driblar a fiscalização tributária, institutos jurídicos adquirem contornos jamais pensados pelo legislador ou pelo intérprete. Regime de bens de matrimônio transforma-se em escudo para a prática de simulações e confusões; usucapiões transformam-se em institutos voltados à fraude à execução; constituição de pessoas jurídicas torna-se instrumento para lavagem de capitais.

O planejamento tributário, concebido para ser instrumento lícito de elisão, muitas vezes é posto no limite frágil que o separa da evasão fiscal, convertendo-se em mecanismo a serviço da sonegação.

É evidente que se deve sempre ter o cuidado de diferenciar as condutas a partir da intenção do agente econômico. Por óbvio, o planejamento tributário é um instrumento lícito a serviço do contribuinte. Na análise de condutas, contudo, deve-se perquirir a real intenção do agente, interpretando-se economicamente os negócios, em busca de aferir a existência de real propósito negocial (business purpose). Nesse aspecto, direito e economia mais uma vez se entrelaçam, não sendo possível interpretar os institutos jurídicos no vácuo, a saber, sob a restrita ótica da dogmática analítica. $O$ estudo da sonegação não pode olvidar as valiosas contribuições das Ciências Sociais que integram a zetética (FERRAZ JÚNIOR, 2014).

José Joaquim Calmon de Passos destaca, sob a ótica processual executiva, a mudança de padrão comportamental do devedor em relação ao patrimônio pessoal. Se, outrora, o patrimônio era dotado de maior transparência e solidez, nos tempos hodiernos, a abstração e a alta liquidez do patrimônio tornam hercúlea a tarefa de cobrança do credor:

Há um século, o patrimônio era relativamente transparente: alguns bens móveis, algumas terras, às vezes uma ou mais casas de campo e alguns rendimentos de investimentos, imobiliários em sua maioria; tudo era facilmente identificável e permanecia suficientemente estável para se fazer conhecido e facilmente apreensível. Em nossos dias, o patrimônio perdeu sua transparência. Os bens do devedor podem ser um móvel de alto custo, mas normalmente são contas em banco em alguma 
parte do país ou no estrangeiro, ganhos diversos, dentre os quais os do trabalho são sem dúvida os mais visíveis, se o devedor tem um emprego estável; participações sociais em algumas sociedades civis imobiliárias disseminadas, ou capitais que se diluem de forma maleável, por meio dos muito sábios expedientes que nos proporciona o direito das sociedades [...]. Em uma palavra, a fortuna se faz mais abstrata, e, ao mesmo tempo, mais discreta e mais móvel e por essas razões infinitamente mais difícil de ser caçada. (PASSOS apud MANCUSO, 2011, p. 109).

A situação é agravada no cenário tributário. De fato, o poder público é o maior credor do país, conforme atestam os números do boletim "Justiça em Números 2018", do CNJ (BRASIL, 2018c). Multiplicamse os casos em que os mecanismos de blindagem patrimonial evasiva escamoteiam-se sob o rótulo do planejamento tributário.

O segundo aspecto concernente à compreensão do fenômeno da sonegação fiscal diz respeito à dimensão territorial brasileira e à forma federativa de Estado. O controle da evasão em território continental é tarefa das mais hercúleas, sendo a dificuldade agravada pelo insuficiente diálogo entre os entes federativos. $\mathrm{E}$, paralelo a isso, o e.commerce e a globalização empresarial potencializam a necessidade de cooperação institucional, incluindo transações realizadas para além do território brasileiro.

\section{Responsabilidade tributária dos grupos societários econômicos de fato}

O exercício da atividade econômica ocorre prevalentemente por meio da empresa, concebida como "atividade econômica organizada para a produção ou circulação de bens e serviços", conforme conceito - de inspiração italiana - constante no artigo 966 do Código Civil brasileiro. O mesmo Código disciplina os institutos basilares da empresa, tais como: estabelecimento empresarial, registro, nome, alterações societárias e responsabilidade dos sócios.

O ordenamento confere estímulos protetivos ao empresário com o objetivo de viabilizar o empreendedorismo, incluindo regras que resguardam a responsabilidade dos sócios de sociedades limitadas e anônimas. Assim, o risco do empreendimento fica restrito ao patrimônio nas formas societárias de empresas de capital, não alcançando bens dos sócios, titulares, administradores e gerentes, os quais apenas são atingidos em casos de práticas tidas como ilícitas ou contrárias ao contrato ou estatuto social.

O benefício alvitrado pelo empresário é o lucro. A contrapartida social, ao lado da circulação de riquezas, da geração de emprego e de demais funções sociais, consiste no pagamento do tributo, o qual financiará o Estado fiscal em busca da implementação de seus objetivos. Contudo o ordenamento constitucional de 1988 criou um modelo jurídico colaborativo, comprometendo, de um lado, a forma federativa a critérios cooperativos de todos os entes estatais e, de outro, impondo a setores privados o compromisso com a função social (art. 5, XXII, XXIII e vários outros; art. 170, II e III).

O sistema acima descreve o modelo de relacionamento entre o Estado fiscal e as empresas, evidenciando que o público e o privado são aliados no financiamento de direitos. O padrão descrito pode sofrer desvios por meio de mecanismos que se voltem à prática de atos evasivos em desfavor do credor fiscal. A edificação de grupos econômicos de fato, de caráter evasivo, situa-se entre os desvios de percurso.

Pensando em sua dinâmica, empresas são pessoas jurídicas que operam individualmente, mas podem fazer alianças ou acordos de diversas espécies (p. ex., consórcios de empresas). Nesse universo de alianças, emergem os grupos econômicos, os quais podem ser classificados, quanto à forma, em grupos econômicos de direito (formalizados nos termos da Lei n. ${ }^{\circ} 6.404 / 1976$, como coligadas e controladas) e em grupos econômicos de fato (sem formalização entre os participantes que, todavia, operam alinhados).

Se o direito societário encontra raízes fincadas no período de transição entre a baixa Idade Média e o início da era moderna, é no século XX, com a sedimentação do capitalismo monopolístico no cenário global, que a formação das grandes aglomerações econômicas ganhou impulso, consoante observa Susy Elisabeth Cavalcanti Koury (2011). Nesse contexto, foram desenvolvidas teorias voltadas a explicar comportamentos patológicos de mercado, as quais no cenário jurídico refletem-se na edificação da teoria da desconsideração de personalidade jurídica, cujo desenvolvimento dogmático é atribuído aos estudos de 
Rolf Serick - empreendidos em solo alemão -, destacando-se a evolução jurisprudencial inicial, conferida, sobretudo, na Inglaterra (BIANQUI, 2010).

Uma importante ressalva impõe-se desde já: a formação de grupos econômicos, de direito ou de fato, não configura per si ato ilícito ou abusivo. Como já referido, as conjunturas econômicas ou negociais que podem levar à formação de grupos econômicos de fato não colocam seus integrantes na ilicitude. $O$ ilícito consiste, isto sim, na composição abusiva de estruturas econômicas voltadas a fraudar credores, notadamente o credor fiscal, como descrito no art. 50 do Código Civil.

Para o que interessa a este estudo, a prática irregular consiste em formar alianças entre pessoas jurídicas diversas - dotadas de regularidade formal, mediante abertura de cadastros na Receita Federal do Brasil e na Junta Comercial estadual respectiva - para fins de blindagem patrimonial voltada exclusivamente a evitar a expropriação em favor do credor tributário. Somam-se à criação de pessoas jurídicas meramente formais a utilização de confusão patrimonial e o compartilhamento de estrutura.

Assim, desenvolve-se uma só atividade econômica real, fracionada em diversas pessoas jurídicas organizadas em grupo informal (algumas até fictícias), concentrando-se os débitos tributários em uma ou mais empresas desprovidas de patrimônio e de atividade econômica efetiva. As riquezas, por sua vez, são apropriadas pelas demais pessoas jurídicas integrantes do grupo de fato.

Considerando a existência de abuso de forma e de personalidade, corrente jurisprudencial tem se inclinado a reconhecer a responsabilidade tributária de todos os integrantes do grupo econômico, à luz do disposto no artigo 124, I, do Código Tributário Nacional, combinado com o art. 50 do Código Civil.

O Direito Tributário não pode ser interpretado no vácuo, uma vez que se trata de segmento dogmático intrinsecamente relacionado à higidez da ordem econômica, pelo que os fatos geradores, para além de uma hermenêutica meramente analítica e linguística, devem ser compreendidos sob a perspectiva econômica. A constatação ora exposta decorre da aplicação do disposto no artigo 20 da Lei de Introdução às Normas do Direito Brasileiro - preceito inspirado no movimento Law \& Economics, proveniente da Escola de Chicago.

De fato, sendo o fato gerador um fenômeno multiplexo, que ultrapassa as cercanias do Direito e adentra em aspectos econômicos, impõe-se que sua interpretação não seja meramente formal e positivista, mas igualmente econômica.

Não importa a pluralidade de estruturas jurídicas se o escopo real é a realização de uma mesma atividade econômica. Assim, o artigo 124, I, do CTN, combinado com o art. 50 do Código Civil, rende ensejo à responsabilidade tributária dos integrantes do grupo econômico de fato evasivo.

A partir do cotejo de julgados recentes, é possível identificar requisitos jurisprudenciais comuns para fins de configuração de grupos econômicos de fato, dentre os quais sobrelevam: unidades econômica e gerencial; unidade de propósitos evasivos; confusão patrimonial; esvaziamento patrimonial voltado a fraudar crédito de terceiros; relação de interdependência; compartilhamento de estrutura operacional; e a ausência de propósito negocial (business purpose). ${ }^{9}$

Destaque-se que a responsabilidade tributária das pessoas físicas e jurídicas envolvidas não decorre per si de pertencerem ao mesmo grupo econômico, mas da prática de abuso de direito, mediante abuso de personalidade jurídica e confusão patrimonial, o que caracteriza ato ilícito (CC, art. 187).

Conquanto formada por diversas pessoas jurídicas sem aliança formal, tem-se uma conjugação de atividades econômicas desenvolvidas por uma só estrutura corporativa real. Há, em essência, um acordo velado entre duas ou mais pessoas jurídicas e físicas para que desempenhem diversos papéis, com objetivo de criar "fachadas" voltadas à evasão. Para tais situações, o Código Tributário Nacional preceitua que a

A análise de temas de fato é geralmente feita por Tribunais Estaduais ou Tribunais Regionais Federais, já que os Tribunais extremos funcionam basicamente para matérias de direito, daí porque se mencionam, como exemplos, julgados do Tribunal Regional Federal da $3^{a}$ Região, dado o volume jurisdicional e o alcance de suas competências jurisdicionais, no qual há frequente análise de grupos econômicos de fato: $2^{a}$ Turma, Al - Agravo de Instrumento n. ${ }^{\circ}$ 5032874-64.2019.4.03.0000, Rel. Desembargador Federal Carlos Francisco, julgado em 10/06/2020; $6^{a}$ Turma, Al - Agravo de Instrumento n. ${ }^{\circ}$ 5002148-15.2016.4.03.0000, Rel. Desembargador Federal Carlos Muta, julgado em 24/04/2020. 
capacidade tributária passiva independe dos aspectos formais de constituição das pessoas jurídicas (CTN, art. 126).

Assim, a partir da interpretação econômica do fato gerador, o ordenamento nacional autoriza a responsabilização tributária dos integrantes do grupo econômico de fato evasivo, sem prejuízos de outras responsabilidades decorrentes, como aquelas que se inserem em âmbito criminal, tipificadas na Lei $n .^{\circ}$ 8.137, de 27 de dezembro de 1990.

A utilização de grupos econômicos para fins de sonegação fiscal tem sido prática recorrente que causa danos fiscais astronômicos ao erário, impactando a implementação de direitos pelo Estado fiscal. Em vista disso, a citada prática deve ser combatida, utilizando-se, entre outros meios, da atuação colaborativa dos entes federativos, que será objeto de considerações no próximo item.

\section{Federalismo colaborativo e os grupos econômicos de fato evasivos}

As competências federativas são igualmente relevantes e, em regra e a priori, não há importância maior do ente nacional em relação a entes subnacionais (notadamente estados e também municípios). Alan Tarr destaca a importância dos espaços subnacionais, muitas vezes relegados à "baixa visibilidade tanto por parte dos cidadãos como parte dos estudiosos" (TARR, 2009), porque análises jurídicas geralmente são centradas em Constituições da República (que, por sua vez, se concentram na descrição da União Federal).

Em vista de o modelo federativo cooperativo adotado pela Constituição de 1988 induzir a mecânicas não competitivas entre entes estatais, a colaboração de todos (o setor privado com o setor público) deve ser feita sob a ótica do compromisso empresarial com a função social (art. $5^{\circ}$, XXII, XXIII e vários outros; art. 170, II e III), ainda que movidos por escolhas livres e concorrenciais voltadas ao lucro. Esse compromisso entre público e privado é ainda maior em se tratando do terceiro setor, que não é objeto deste estudo, em razão de geralmente ser beneficiado com imunidades ou isenções de tributos.

Fiscalizar e reprimir a sonegação fiscal, otimizando os mecanismos de performance tributária, é tarefa que envolve elevado grau de dificuldade, considerando a criatividade e a diversificação dos meios abusivos pelos agentes econômicos que se valem de instrumentos de evasão.

É verdade que a ordem constitucional brasileira de 1988 centraliza muitas competências na União Federal, quando o federalismo cooperativo brasileiro é comparado com os de outros países (TARR, 2009), mas as dificuldades são grandes no Brasil, considerando as dimensões continentais do território e os "vácuos de poder" decorrentes do regime de descentralização federativa. Sobre esse último aspecto, Ferraz Junior e Greco (1998), ao discorrerem acerca do federalismo fiscal solidário ou cooperativo brasileiro, listaram cinco desafios que carecem de tratamento, sendo três de ordem política, quais sejam: a equalização da carga tributária global, a distribuição de encargos públicos e a guerra fiscal; bem como dois desafios de ordem técnica, a saber: a definição de critérios claros de fixação da competência tributária e a neutralidade da tributação.

Reside no segundo desafio de ordem política o problema das indefinições e da falta de coordenação quanto à realização de competências administrativas, incluindo aquelas de cunho fiscalizatório. Também é nesse segundo desafio de ordem política que as condutas dolosas de sonegação tributária por grupos econômicos de fato se tornam ainda mais graves, frustrando a lógica jurídica do federalismo cooperativo atrelado à solidariedade e à colaboração legítima da sociedade civil, além de primados da própria concorrência empresarial. Ofender vetores do sistema jurídico é relevante, sobretudo, porque essa atitude dos contribuintes tem efeitos visíveis e diretos na construção de meios para a concretização de direitos fundamentais.

Não só intuitivamente, mas também por máxima de experiência, sabe-se que há discursos críticos à elevada carga tributária, usados como "salvo conduto" para que contribuintes se esquivem de reprovações éticas por não recolherem tributos, ainda que infringindo, conscientemente, não só a solidariedade e a colaboração positivadas no ordenamento jurídico (inclusive com reflexos no âmbito penal), mas também a competitividade em detrimento de empreendimentos que cumprem regularmente suas obrigações. Quando a sonegação é levada a efeito por grupos econômicos de fato, o efeito catalisador de suas irregularidades 
se dá não apenas em desfavor de competências tributárias federativas cooperativas, mas também da ordem econômica.

As estruturas econômicas evasivas espraiam-se por todo o território nacional com o escopo de maximização de lucros à custa do dever fundamental de pagamento de tributos. Aproveitando-se do vácuo de poder deixado pelos problemas do federalismo fiscal brasileiro, fixam sedes fictícias em domicílios fiscais cujos impostos possuem alíquotas menores, por exemplo, e utilizam-se das "guerras fiscais" em proveito próprio. A tais grupos interessa que os desafios do federalismo fiscal brasileiro permaneçam inatacados.

Os mecanismos federativos lastreados na simples autonomia não são suficientes para coibir preventiva e repressivamente a formação de grupos econômicos de fato no território nacional. Esse problema se potencializa em razão do e.commerce e da globalização empresarial, impondo novos mecanismos de cooperação institucional para combater essas práticas ilícitas em tramas envolvendo atividades para além do território brasileiro.

A melhoria da performance fiscal requer, portanto, a atuação harmônica e inteligente das entidades federativas, sob a coordenação da União - como police decision maker -, e a atuação eficiente dos estados e municípios - como police makers, ${ }^{10}$ erigindo-se uma rede de colaboração para implementação de política pública ${ }^{11}$ de prevenção e repressão à formação de grupos econômicos abusivos.

As diferentes competências tributárias não são empecilho à atuação uniforme e coordenada entre os entes federativos. Considerando as semelhanças nas bases tributárias, as quais recaem, em todos os casos, sobre propriedade, consumo ou rendimentos, há coincidentes interesses das entidades federativas na formatação de um sistema de combate aos grupos econômicos fraudulentos.

A coordenação da União não decorre tão somente da circunstância de ser a maior redistribuidora de recursos por meio de transferências voluntárias e constitucionais, mas igualmente do fato de deter posição central, que habilita o ente federal a empreender o monitoramento estatístico e casuístico, notadamente interestadual, das fraudes, as quais poderiam ser acompanhadas harmonicamente com estados e municípios.

Novas ferramentas começam a se mostrar viáveis, como Big Data, que permite cruzamento relevante de informações, o que pode ser alavancado com parcerias entre instituições públicas brasileiras e internacionais. A inteligência artificial também aparece como fator relevante para a avaliação dessas informações, conjugando dados de operações realizadas por integrantes de grupos econômicos de fato.

Reside na colaboração coordenada a chave para a formatação de uma rede harmônica e inteligente que atuaria no combate à sonegação fiscal sistemática, mediante compartilhamento de dados e compartilhamento coordenado de estrutura estatal. Em favor de ampliar os ganhos de performance alvitrados pela Constituição, é imprescindível construir mecanismos que ultrapassem as barreiras formais do federalismo e do diálogo formal entre a União e espaços subnacionais, superando-se desafios em favor dos ideais republicanos e da otimização da capacidade arrecadatória, tendo como fim mediato o fortalecimento dos direitos fundamentais.

Por sua configuração dissimulada e fracionada em mais de uma pessoa jurídica, grupos econômicos de fato têm configuração mais complexa quando comparados a outros empreendimentos, de tal modo que o combate a seus efeitos depende de rede colaborativa alimentada tanto pelo setor público (a partir do federalismo cooperativo) como pelo próprio setor privado, prejudicado pela concorrência desleal da sonegação.

É mister, pois, constatar os benefícios decorrentes de um federalismo fiscal colaborativo, que se coordene para se apropriar das externalidades econômicas positivas decorrentes da atuação em rede no combate à evasão fiscal. Centrais de informações tributárias, formadas em parceria entre os entes que compõem o federalismo cooperativo brasileiro (sob a coordenação da União Federal, mas contando também com o Distrito Federal, os estados e os municípios, escoradas no art. 198 e art. 199, ambas do Código Tributário Nacional), subordinadas ao sigilo fiscal e com poderes controláveis de acesso a informações definidos em

\footnotetext{
Acerca das relações verticais na federação, abordando a distinção entre police makers e police decision makers, conferir Arretche (2012).

Política pública, conforme explicita Maria Paula Dallari Bucci (1996, p. 140-141), é "o processo de escolha dos meios para a realização dos objetivos do governo, com a participação dos agentes públicos e privados. Políticas públicas são programas de ação do governo, para a realização de objetivos determinados, num espaço de tempo certo".
} 
lei (ponderando limites da privacidade com a igualdade e com a justiça fiscal sob o viés da capacidade contributiva), são ferramentas indispensáveis para que o efeito catalisador da sonegação tributária de grupos econômicos de fato sejam minimizados, diminuindo a gravidade dos desequilíbrios orçamentários estatais para que direitos fundamentais prestacionais tenham contrapartida em deveres igualmente fundamentais.

\section{Conclusão}

A procura por alternativas para a solução da crise fiscal brasileira abrange dois caminhos que se complementam. O primeiro envolve ajustes na despesa pública, por meio de controles sobre a execução orçamentária, bem como alterações estruturais, a exemplo da reforma da previdência. O segundo, por sua vez, abarca o desafio de aumentar a arrecadação sem aumento formal da carga tributária, por meio da utilização de mecanismos que reforcem a performance fiscal.

Em busca de melhorias para a boa administração tributária, as divisas e as guerras, que, por tanto tempo, opuseram os entes federativos, devem ceder espaço a um modelo colaborativo de federalismo que integre a União, como police decision maker, e os estados e municípios, como police makers, formatando-se um sistema de combate preventivo e repressivo à formação de grupos econômicos de fato voltados à evasão fiscal.

Convém aos gestores a compreensão holística do sistema tributário, que não se limita a servir como espaço de disputas entre entes federativos por receitas setoriais, mas corresponde ao terreno fértil para o desenvolvimento dos direitos a serem implementados pela República Federativa do Brasil.

A dissimulada e fracionada atividade de grupos econômicos de fato, que resulta em sonegação tributária, com efeito catalisador tanto na arrecadação estatal quanto na competitividade do setor privado, deve ser enfrentada por rede colaborativa formada a partir do federalismo cooperativo (coordenada pela União Federal) e também integrada pelo setor privado, prejudicado pela concorrência desleal do sonegador. Com poderes controláveis de acesso a informações definidos em lei e subordinadas ao sigilo fiscal, devem ser criadas centrais colaborativas de informações (amparadas no art. 198 e art. 199, ambos do Código Tributário Nacional) para minimizar os desequilíbrios orçamentários estatais no custeio de direitos fundamentais prestacionais e para impor a correspondente e igualitária tributação como dever fundamental.

\section{Referências}

ARRETCHE, Marta. Democracia, federalismo e centralização no Brasil. Rio de Janeiro: FGV: Fiocruz, 2012.

BAGNOLI, Vicente. Direito e poder econômico: os limites jurídicos do imperialismo frente aos limites econômicos da soberania. Rio de Janeiro: Elsevier, 2009.

BARCELLOS, Ana Paula de. A eficácia jurídica dos princípios constitucionais: o princípio da dignidade da pessoa humana. 2. ed. Rio de Janeiro: Renovar, 2008.

BARROSO, Luís Roberto. Curso de direito constitucional contemporâneo. 5. ed. São Paulo: Saraiva, 2015.

BECHO, Renato Lopes. Responsabilidade tributária de terceiros. São Paulo: Saraiva, 2014.

BIANQUI, Pedro Henrique Torres. Desconsideração judicial da personalidade jurídica pela óptica processual. 2010. Dissertação (Mestrado em Direito Processual) - Departamento de Direito Processual, Universidade de São Paulo, São Paulo, 2010.

BINENBOJM, Gustavo. Da supremacia do interesse público ao dever de proporcionalidade: um novo paradigma para o direito administrativo. Revista de Direito Administrativo, Rio de Janeiro, v. 239, p. 1-32, jan. 2005. Disponível em: http://bibliotecadigital.fgv.br/ojs/index.php/rda/article/view/43855. Acesso em: 12 jul. 2020.

BRASIL. Ministério da Fazenda. Receita Federal. Carga tributária no Brasil 2017: análise por tributo e bases de incidência. Brasília: Ministério da Fazenda, 2018a. Disponível em: http://receita.economia.gov. 
br/dados/receitadata/estudos-e-tributarios-e-aduaneiros/estudos-e-estatisticas/carga-tributaria-no-brasil/ carga-tributaria-2017.pdf. Acesso em: 04 jul. 2018.

BRASIL. Procuradoria-Geral da Fazenda Nacional. PGFN em Números: dados de 2017. Brasília: Procuradoria-Geral da Fazenda Nacional, 2018b. Disponível em: http://www.pgfn.fazenda.gov.br/noticias/ arquivos/2018/pgfn_em_numeros_final_2_web.pdf/view. Acesso em: 15 jun. 2020.

BRASIL. Conselho Nacional de Justiça. Justiça em Números 2018. Brasília: Conselho Nacional de Justiça, 2018c. Disponível em: http://www.cnj.jus.br/pesquisas-judiciarias/ justicaemnumeros/2016-10-21-13-13-04/pj-justica-em-numeros. Acesso em: 07 jul. 2019.

BRASIL. Tribunal Regional Federal da $3^{a}$ Região. Agravo de Instrumento $n^{\circ}$ 503287464.2019.4.03.0000. Direito tributário. Autonomia da personalidade jurídica. Teoria maior da desconsideração. Grupo econômico de fato. Fundamentos normativos. Medida excepcional. Configuração no caso concreto. Agravo de instrumento desprovido. Relator: Des. Federal Carlos Francisco, 12 de junho de 2020. Disponível em: https://www.jusbrasil.com.br/diarios/301731077/trf-3judicial-i-12-06-2020-pg-296?ref=feed. Acesso em: 12 jul. 2020.

BRASIL. Tribunal Regional Federal da $3^{a}$ Região. Agravo de Instrumento $n^{\circ}$ 500214815.2016.4.03.0000. Direito processual civil. Tributário. Agravo de instrumento. Execução fiscal. Fraude à execução e grupo econômico de fato. Alienações de imóveis. Confusão patrimonial. Supressão de instância. Apreciação restrita a matérias de ordem pública. Prescrição. Litispendência. Devido processo legal. Instauração de incidente de desconsideração inversa de personalidade jurídica. Descabimento em execução fiscal. Recurso desprovido. Relator: Des. Federal Carlos Muta, 29 de abril de 2020. Disponível em: https://www.jusbrasil.com.br/diarios/294986904/trf-3-judicial-i-29-04-2020-pg-475?ref=feed. Acesso em: 12 jul. 2020.

BUCCI, Maria Paula Dallari. As políticas públicas e o direito administrativo. Revista Trimestral de Direito Público, São Paulo, v. 13, p. 134-144, 1996.

CARVALHO, Cristiano. Direito tributário e análise econômica do direito: uma introdução. In: LIMA, Maria Lúcia L. M. (coord.) Agenda contemporânea: direito e economia: 30 anos de Brasil. São Paulo: Saraiva, 2012. v. 3. p. 27-51.

CATARINO, João Ricardo. Apresentação. In: FILIPPO, Luciano Gomes. A performance no direito tributário. São Paulo: Almedina, 2016. p. 07-11.

CHEVALLIER, Jacques. L'état post-moderne. 3. ed. Paris: Librarie Générale de Droit et de Jurisprudence - L.G.D.J., 2008. (Série Politique)

COOTER, Robert; ULEN, Thomas. Law \& economics. 6. ed. Boston: Addison Wesley, 2012.

DI PIETRO, Maria Sylvia Zanella. Parcerias na administração pública. 5. ed. São Paulo: Atlas, 2006.

DUQUE, Marcelo Schenk. Curso de direitos fundamentais. São Paulo: Revista dos Tribunais, 2014.

FERRAZ JÚNIOR, Tercio Sampaio. A ciência do direito. 14. ed. São Paulo: Atlas, 2014.

FILIPPO, Luciano Gomes. A performance no direito tributário. São Paulo: Almedina, 2016.

FRANCISCO, José Carlos. Estado democrático de direito, políticas públicas e novos modelos de governanças internacionais. In: ALMEIDA, Fernando Dias Menezes de et al. (org.). Direito constitucional, estado de direito e democracia: homenagem ao Prof. Manoel Gonçalves Ferreira Filho. São Paulo: Editora Quartier Latin do Brasil, 2011. v. 1. p. 413-431.

GODOY, Arnaldo Sampaio de Moraes. Transação tributária: introdução à justiça fiscal consensual. Belo Horizonte: Fórum, 2017.

GRECO, Marco Aurélio. Planejamento tributário. 3. ed. Rio de Janeiro: Dialética, 2011.

GRECO, Marco Aurélio; FERRAZ JUNIOR, Tercio Sampaio. Desafios do federalismo fiscal brasileiro.

Revista do Instituto dos Advogados de São Paulo, São Paulo, ano 1, n. 2, p. 97-104, jul./dez. 1998. 
HOLMES, Stephen; SUSTEIN, Cass R. The costs of rights: why liberty depends on taxes. New York: W. W. Norton, 2000.

KLARMAN, Michael. Speaker's Notes. In: HART LECTURE AT GEORGETOWN LAW CENTER: Courts, Social Change, and Political Backlash, 31, 2011, Washington, D.C. Annals [...]. Washington, D.C.: Georgetown, 2011. Disponível em: http://tinyurl.com/bz4cwqk. Acesso em: 25 jul. 2019.

KOURY, Susy Elisabeth Cavalcante. A desconsideração da personalidade jurídica e os grupos de empresas. 3. ed. Rio de Janeiro: Forense, 2011.

MACKAAY, Ejan; ROUSSEAU, Stéphane. Análise econômica do direito. Tradução: Rachel Sztjan. 2. ed. São Paulo: Atlas, 2015.

MAMEDE, Gladston; MAMEDE, Eduardo Cotta. Holding familiar e suas vantagens: planejamento jurídico e econômico do patrimônio e da sucessão familiar. 9. ed. São Paulo: Atlas, 2017.

MANCUSO, Rodolfo de Camargo. Acesso à justiça: condicionantes legítimas e ilegítimas. São Paulo: Revista dos Tribunais, 2011.

MARINONI, Luis Guilherme; MITIDIERO, Daniel; SARLET, Ingo Wolfgang. Curso de direito constitucional. 6. ed. São Paulo: Saraiva, 2017.

MEDAUAR, Odete. O direito administrativo em evolução. 3. ed. Brasília: Gazeta Jurídica, 2017. NABAIS, José Casalta. O dever fundamental de pagar impostos. Coimbra: Almedina, 1998.

PEIXOTO, Daniel Monteiro. Responsabilidade tributária e os atos de formação, administração, reorganização e dissolução de sociedades. São Paulo: Saraiva, 2012.

PORTO, Éderson Garin. A colaboração no direito tributário. Porto Alegre: Livraria do Advogado, 2016.

POSNER, Richard. Economic analysis of law. 9. ed. New York: Wolters Kluwer Law \& Business, 2014.

POSNER, Richard. Para além do direito. Tradução: Evandro Silva. São Paulo: Martins Fontes, 2009.

ROQUE, Jorge. Planejamento tributário deve ser feito com propósito negocial. Conjur, São Paulo, 27 jan. 2014. Disponível em: https://www.conjur.com.br/2014-jan-27/jorge-roque-planejamento-tributariofeito-proposito-negocial. Acesso em: 14 jul. 2019.

SARLET, Ingo Wolfgang. Os direitos sociais como direitos fundamentais: contributo para um balanço aos vinte anos da Constituição Federal de 1988. Revista do Instituto de Hermenêutica Jurídica, Belo Horizonte, v. 20, p. 163-206, 2008.

SONEGÔMETRO. Quanto custa o Brasil. 2020. Disponível em: http://www.quantocustaobrasil.com.br/. Acesso em: 07 de jul. 2018.

TARR, G. Alan, Federalismo e espaço constitucional subnacional. Revista Brasileira de Estudos

Constitucionais - RBEC, Belo Horizonte, ano 3, n. 10, p. 95-126, abr./jun. 2009.

TORRES, Heleno Taveira. Prefácio. In: FILIPPO, Luciano Gomes. A performance no direito tributário. São Paulo: Almedina, 2016. p. 13-15.

ZYKBERSTAJN, Decio; SZTAJN, Rachel. Análise econômica do direito e das organizações. In:

ZYKBERSTAJN, Decio; SZTAJN, Rachel (coord.). Direito e economia: análise econômica do direito e das organizações. Rio de Janeiro: Elsevier, 2005. p. 17-28.

Recebido em: 13/08/2019

Aprovado em: 30/10/2019 